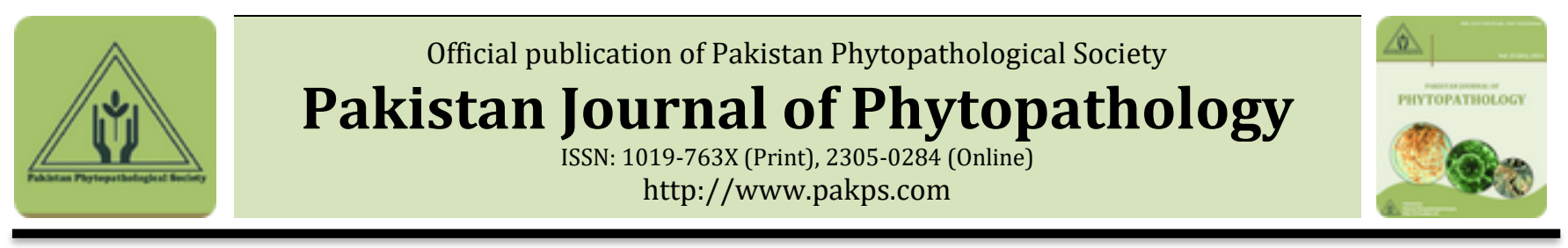

\title{
EFFECT OF SOME ESSENTIAL OILS ON THE GROWTH AND DEVELOPMENT OF FRUIT ROT OF LEMON CAUSED BY ASPERGILLUS NIGER UNDER IN-VITRO CONDITIONS
}

\author{
a,bAhmed Ali, bManzoor A. Abro*, bRehana N. Syed, bMoeezullah Khan, b,cHassan Saeed \\ aDepartment of Agriculture \& Cooperative, Research Wing, Balochistan, Pakistan. \\ ${ }^{b}$ Department of Plant Pathology, Sindh Agriculture University, Tando Jam, Pakistan. \\ 'Department of Agriculture \& Cooperative, Extension Wing, Balochistan, Pakistan.
}

\section{A B S T R A C T}

It is common observations that during storage, transportation and marketing fruits and vegetables suffer from many postharvest diseases. Generally the diseases are controlled by applying different chemicals in the form of fungicides. On the other hand, these fungicides are also hazardous for health and disturb the equilibrium of the natural environment. In this regard, researchers have found that certain plant essential oils not only keep away the insects but also show fungicidal actions against some plant pathogens. The aim of current investigation is to find out some suitable and effective essential oils against the growth fruit rot of lemon caused by Aspergillus niger under in-vitro conditions. For this purpose, pathogenicity test against A. niger was performed. The antifungal components of some essential oils like clove, tarpin, neem, castor, chamomile, and rose oil were carried out at different doses i.e. $50 \mu \mathrm{l}$ and $100 \mu \mathrm{l}$ to find out their effectiveness against $A$. niger. The results showed that, high severity of disease was determined through the cut method of inoculation as compared to the injection method. Minimum colony growth $(1.11 \%$ and $0.55 \%)$ was examined when plates treated with clove oil at the dosage of $50 \mu$ and $100 \mu$ followed by tarpin oil $(42.22 \%$ and $38.89 \%)$, neem oil $(42.96 \%$ and $41.11 \%)$, castor oil $(52.96 \%$ and $50.00 \%)$ and chamomile oil $(71.85 \%$ and $67.77 \%)$ respectively. In comparison to control (100\%), maximum growth $(91.85 \%$ and $89.62 \%)$ was observed when treated with rose oil at the dosage of $50 \mu \mathrm{l}$ and $100 \mu \mathrm{l}$. When the inoculated lemon fruits were treated with aqueous solution of essential oils, it was observed that minimum rotting (12.53\%) was recorded for clove oil followed by neem oil (13.30\%), tarpin oil $(13.42 \%)$, rose oil (14.27\%), castor oil $(15.16 \%)$ and chamomile oil $(17.25 \%)$, respectively as compared to control (23.37\%). On the basis of present investigation it was concluded that clove oil is highly effective against linear colony growth of A. niger under in-vitro conditions.

Keywords: Essential oils, Aspergillus niger, Pathogenicity, Cut and Injection Methods

\section{INTRODUCTION}

Across 100 countries of the world, lemon fruit a crop of winter season has grown for its commercial purposes (Terol et al., 2014).The cross between citron (Citrus medica L.) and sour orange thought to produce a hybrid variety of fruit known as lemon. Lemon fruits are available in round, oblong, or elongated shapes. China,

Submitted: November 28, 2018

Revised: December 14, 2018

Accepted for Publication: December 24, 2018

* Corresponding Author:

Email: mmanzoorabro@hotmail.com

(C) 2017 Pak. J. Phytopathol. All rights reserved.
U.S.A, Brazil, Mexico, Spain and India are the world's largest producing countries contributing approximately two-third of global production of citrus fruit (Sabulal et al., 2006). Worldwide, Pakistan being an agricultural country, ranked $10^{\text {th }}$ in producing citrus fruit (Sabir et al., 2010). Lemon is a rich source of vitamin ' $C$ ' and plays an important role in health promotion. Lemon fruits contain less proportion of proteins and fats, providing sucrose, glucose and fructose as carbohydrates (Spina et al., 2008). Lemon fruits are also a good source of some dietary fiber which preventing gastrointestinal disease and lowering the cholesterol level in the blood. 
Most important plant pathogens are fungi, bacteria, phytoplasmas and viruses. Among such pathogens, fungi can cause severe losses in fruits as well as in vegetables. Lemon due to low pH (less than 4) and high moisture contents make them susceptible to various fungi (Moss, 2012). The fruit rot of lemon caused by Aspergillus niger is one of the major postharvest disease which may cause considerable losses to the lemon growers. The disease caused by A. niger is more sever in rainy season in lemon fruits. In Pakistan, storage, inappropriate method of packing, transportation and marketing become the cause of nearly $40 \%$ loss to the lemon fruits (Samuel et al., 2017). Most post-harvest pathogens (Penicillium, Alternaria, Aspergillus, Diplodia, Phomopsis) are quite selective in their host and $\mathrm{pH}$. Most of the fungi attack lemon fruits due to weak defense mechanism in term of low $\mathrm{pH}$ which is less than 4 (Ladanyia and Ladaniya, 2010).

Over many decades, attempts and efforts have been made so as to prevent and control the plants from such heavy loss (Inouye et al., 2006). In this regard, scientists have developed synthetic fungicides to check the growth of such pathogens in host plants. Obviously, these pesticides are able and highly effective in controlling a variety of pre and post harvest diseases of vegetables and fruits. On the other hand, the continuous and repeated use of various fungicides may disturb the equilibrium of ecosystems and produces high threats for health than insecticides and herbicides (Gomi et al., 2003). Susceptibility of lemon fruits to rotting has been associated with ripeness and over ripeness of the fruits and long storage periods.

Therefore, the challenges have been emerged to develop alternative method which is safer and eco-friendly and causes less risk to the health of human lives and nature. In this regard, researchers have shown an interest for using non-toxic alternatives instead of synthetic fungicides. There are about 2600 species of plants out of which 700 are noted for their use as medicinal herbs.

$$
\text { Disease incidence }(\%)=\frac{\text { Number of diseased fruits }}{\text { Total number of fruits }} \times 100
$$

Isolation, identification and multiplication of the causal fungus: The infected portion of lemon fruits was cut into small pieces of 3 to $4 \mathrm{~mm}$, surface sterilized with $5 \%$ commercial bleach for 2 minutes. The sterilized pieces were washed twice with sterilized water and shifted over the surface of sterilized filter paper for drying and then sterilized portions were placed in Petri dishes containing
Different essential oils and its use have been found to be more effective and an alternative method against pathological breakdown of certain pathogens of lemon fruits as compare to other methods (Klieber et al., 2002; Ahmed et al., 2007).The natural and complex compound properties of plant essential oils make them able to act as an antioxidant and antimicrobial against certain pathogens (Bakkali et al., 2008). The biodegradability of EOs compounds has shown an effective control against post-harvest diseases like; green mould, blue mould and sour rot of lemon fruits (Arras and Usai, 2001). No doubt, postharvest fungal disease of lemon fruit causes significant economic losses to the growers. Yet satisfactory attention has not been given on this group of diseases. Due attention must be given to reduce the risk of chemicals methods hence the current study was conducted to isolate and identified and afterwards find the potential of some EOs clove, tarpin, neem, castor, chamomile and rose oil for the control of fruit rot of lemon with the following objectives and techniques. First of all the fungus was isolated from the diseased lemon fruits and the identification was made using microscopic technique. The identified fungus was then purified for further use. The pathogenicity test against the Aspergillus niger was performed. The antifungal potential of different essential oils was checked on the linear colony growth of most predominant fungus. Then, further the efficacy of some aqueous solution of essential oils against the disease development can be checked and evaluated on the disease development of fruit rot of lemon.

\section{MATERIALS AND METHODS}

Survey and sampling: Survey and sampling of infected lemon fruits were done at the local market of Tando Jam and Hyderabad city.

Disease incidence: The disease incidence of rotted lemon fruits can be calculated through the following formula.
PDA medium. All Petri plates were kept in incubator at $25 \pm 2^{\circ} \mathrm{C}$ temperature for 7 days to observe sporulation of the fungi. The fungus was identified through microscope with different magnifications, the pure culture of fungus was made, maintained and multiplied for future use. The following formula gives information on the frequency of isolated fungi. 


$$
\text { Frequency }(\%)=\frac{\text { Number of pieces colonized by the fungus }}{\text { Total no of pieces cultured in plates }} \times 100
$$

Pathogenicity test of the most predominant fungus: Pathogenicity test of predominant fungus $(A$. niger) was conducted on six [6] healthy, mature and fresh lemon fruits through two different methods i.e. wound and injection method. The pathogen disc from 8-10 days old culture plates was taken and inserted into [03] fresh lemon fruits through cut method and [03] lemon fruits were inoculated by the solution of pathogen [ $1 \mathrm{ml}$ of pathogen solution] through injection method. The inoculated portion of lemon fruits were covered with paraffin film and then placed in plastic bags. Lemon fruits were monitored daily for disease development.

To evaluate the efficacy of various essential oils on the linear colony growth of the casual fungus: The efficacy of different essential oils such as clove, neem, tarpin, castor, chamomile and rose oil was examined under in-vitro conditions against $A$. niger. The essential oils were used, with two different doses i.e. $50 \mu \mathrm{l}$ and $100 \mu \mathrm{l}$. Pathogens disc approximately (5mm) from 8-10 days old reserved pure culture were taken and placed in the middle of Petri dishes containing PDA and then mounted in an incubator at $28^{\circ} \mathrm{C}$. Petri dishes without EOs were served as control. Day wise radial colony growth of $A$. niger was recorded till the Petri dishes will completely fill with the fungus in any treatment.

Effect of some essential oils on the growth and development of fruit rot of lemon under in-vitro conditions: Similarly, effects of EOs were checked against the disease development and growth by the method introduced by (Lassois et al., 2008) with little modification. In this method, the collected infected samples of lemon fruits were first washed with tap water. After that the lemon fruits were sterilized with $5 \%$ commercial bleach for 2 minutes. The fresh and healthy specimens of lemon fruits were inoculated with 8-10 days old culture of A. niger. The selected essential oils were added in distilled water at the rate of $(1 \mathrm{ml} / 300 \mathrm{ml})$ with a drop of tween -20 as to mix the oil in water. After a day the inoculated lemon fruits were immersed for about 5 minutes in the aqueous solution of selected essential oils. The lemon fruits specimen treated with different EOs were put separately on the tissue papers at $20^{\circ} \mathrm{C}$ with humidity of $80 \%$. The treated samples were then observed daily for the growth of fungal pathogen. The decrease in disease development showed the effect of EOs. The rotting (\%) in the inoculated lemon fruits in aqueous solution of EOs can be calculated through following formula.

$$
\text { Rotting }(\%)=\frac{\text { Rotted portion of the fruit }}{\text { Total fresh area of the fruit }} \times 100
$$

\section{RESULTS}

This study was carried out to find the effect of some essential oils on the growth and development of fruit rot of lemon caused by Aspergillus niger under in-vitro conditions. The pathogenicity test against $A$. niger was performed. The antifungal potential of different essential oils like clove, tarpin, neem, castor, chamomile and rose oil was carried out at different doses i.e. $50 \mu \mathrm{l}$ and $100 \mu$ l to find out the effective and suitable oil for the growth inhibition of $A$. niger. The result indicates that high severity of disease was observed through the cut method of inoculation as compared to injection method (Figure 1). The results regarding the linear colony growth of $A$. niger under different essential oils were presented in (Table 1). The data clarified that minimum colony growth of $A$. niger ( 1.00 and $0.5 \mathrm{~mm}$ ) was examined under clove oil at the dosage of $50 \mu \mathrm{l}$ and $100 \mu \mathrm{l}$ followed by tarpin oil (38.33 and $33.83 \mathrm{~mm}$ ), neem oil (39.16 and $37.00 \mathrm{~mm})$, castor oil (46.50 and $44.50 \mathrm{~mm}$ ) and chamomile oil (64.16 and $60.33 \mathrm{~mm}$ ), respectively. Maximum colony growth of $A$. niger (82.66 and 80.33 $\mathrm{mm}$ ) was observed under rose oil at the dosage of $50 \mu \mathrm{l}$ and $100 \mu \mathrm{l}$. Under control the A. niger showed $(90 \mathrm{~mm}$ ) colony growth. On the basis of means clove oil ranked $1^{\text {st, }}$ tarpin oil ranked $2^{\text {nd }}$, neem oil ranked $3^{\text {rd }}$, castor oil ranked $4^{\text {th }}$, chamomile oil ranked $5^{\text {th }}$, rose oil ranked $6^{\text {th }}$ for controlling colony growth of A.niger under in-vitro conditions presented in (Figure 2). Statistical analysis reveals that there was significant difference in the linear colony growth of $A$. niger among the essential oils at different dozes. The results showed that mean minimum rotting $(12.53 \%)$ was recorded for clove oil followed by neem oil $(13.30 \%)$, tarpin oil $(13.42 \%)$, rose oil $(14.27 \%)$, castor oil $(15.16 \%)$ and chamomile oil (17.25\%), respectively (Table 2). Maximum rotting $(23.37 \%)$ was recorded for under control shown in (Figure 3). The analysis of obtained data revealed that there was significant difference in rotting percentage between the essential oils on different days. 
Table 1. Effect of different essential oils on the linear colony growth of A. niger

\begin{tabular}{clccc}
\hline \multirow{2}{*}{ Sr. No. } & \multirow{2}{*}{ Essential oils } & \multicolumn{2}{c}{ Doses } & \multirow{2}{*}{ Mean } \\
\cline { 2 - 4 } & & $50 \mu \mathrm{l}$ & $100 \mu \mathrm{l}$ & $0.75 \mathrm{f}$ \\
\hline 1. & Clove oil & $1.00 \mathrm{~h}$ & $0.50 \mathrm{~h}$ & $36.08 \mathrm{e}$ \\
\hline 2. & Tarpin oil & $38.33 \mathrm{f}$ & $33.83 \mathrm{~g}$ & $38.08 \mathrm{e}$ \\
\hline 3. & Neem oil & $39.16 \mathrm{f}$ & $37.00 \mathrm{f}$ & $45.50 \mathrm{~d}$ \\
\hline 4. & Castor oil & $46.50 \mathrm{e}$ & $44.50 \mathrm{e}$ & $62.25 \mathrm{c}$ \\
\hline 5. & Chamomile oil & $64.16 \mathrm{c}$ & $60.33 \mathrm{~d}$ & $81.50 \mathrm{~b}$ \\
\hline 6. & Rose oil & $82.66 \mathrm{~b}$ & $80.33 \mathrm{~b}$ & $90.00 \mathrm{a}$ \\
\hline
\end{tabular}

Table 2. Evaluation of rotting (\%) of lemon fruits through direct contact with aqueous solution of essential oils

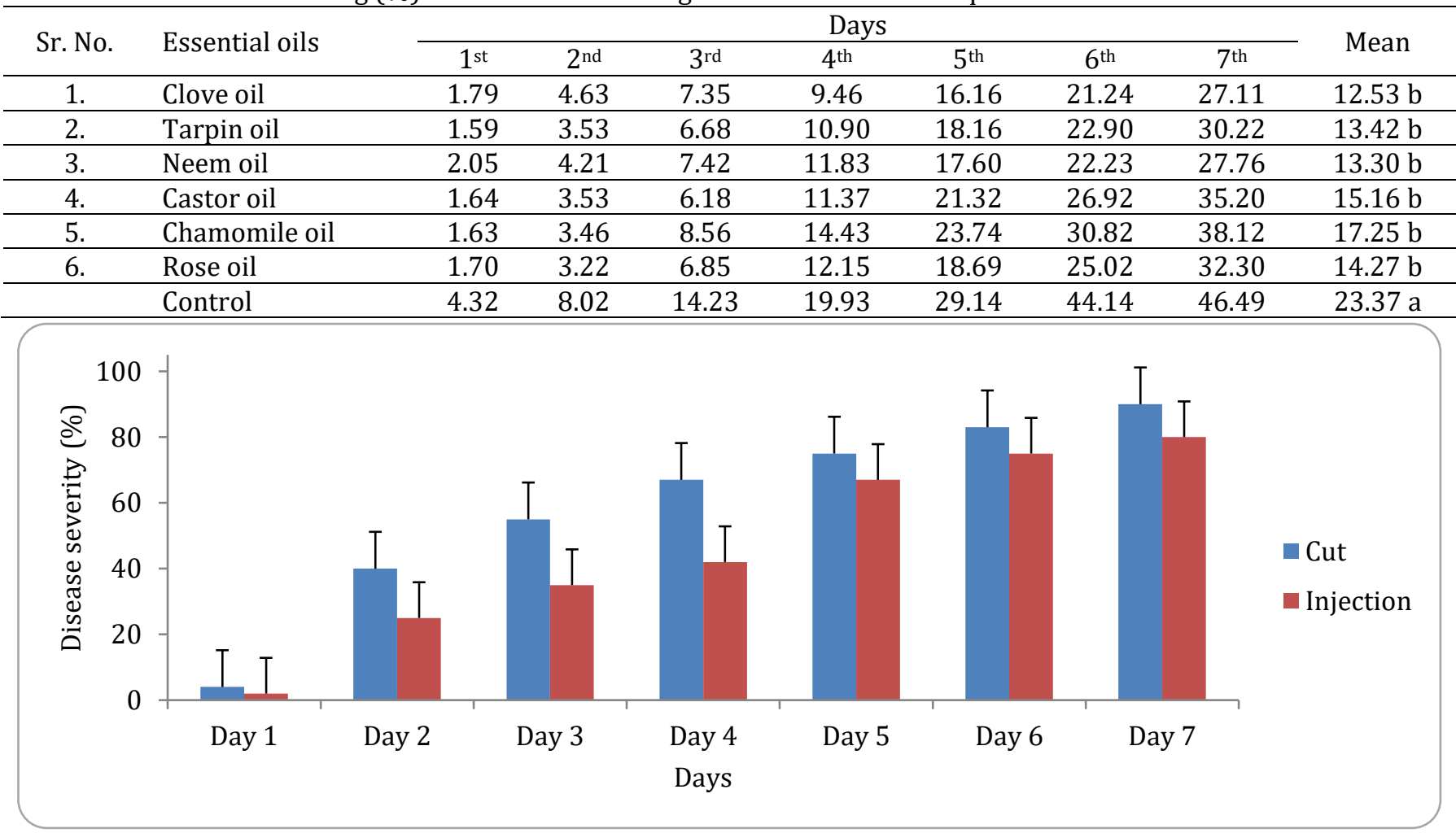

Figure 1. Pathogenicity test against Aspergillus niger

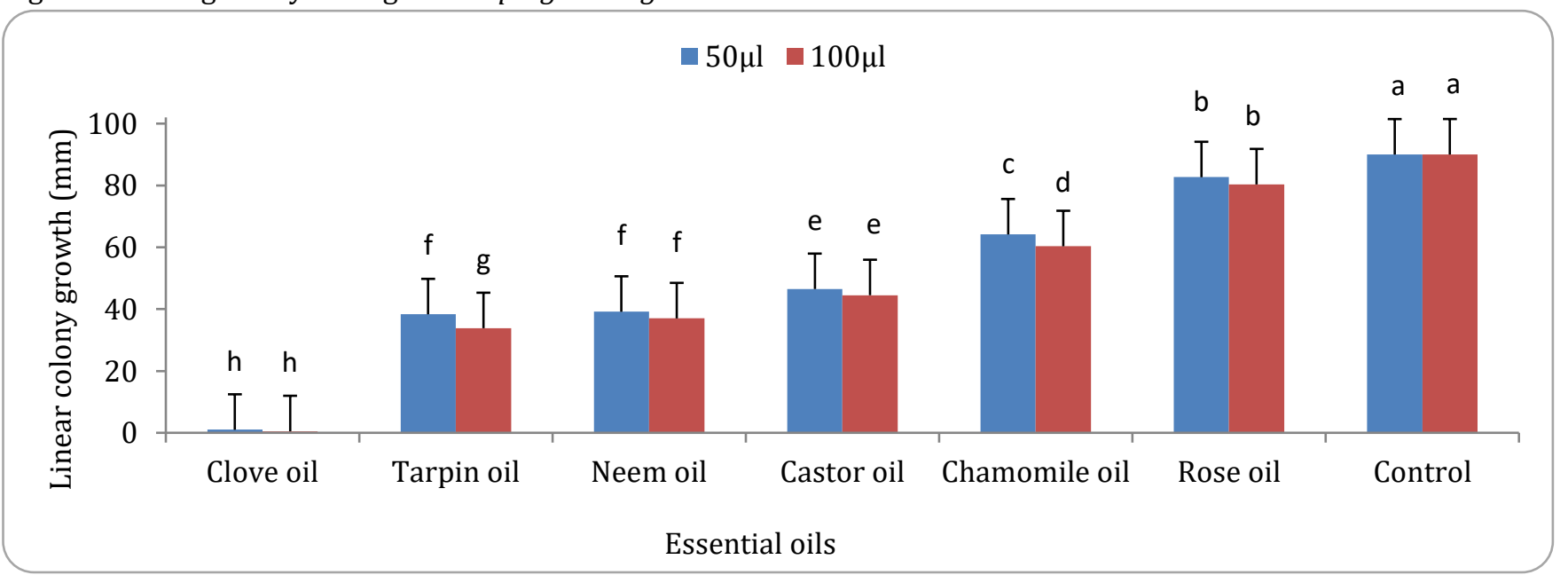

Figure 2. Effect of different essential oils on the linear colony growth of Aspergillus niger 


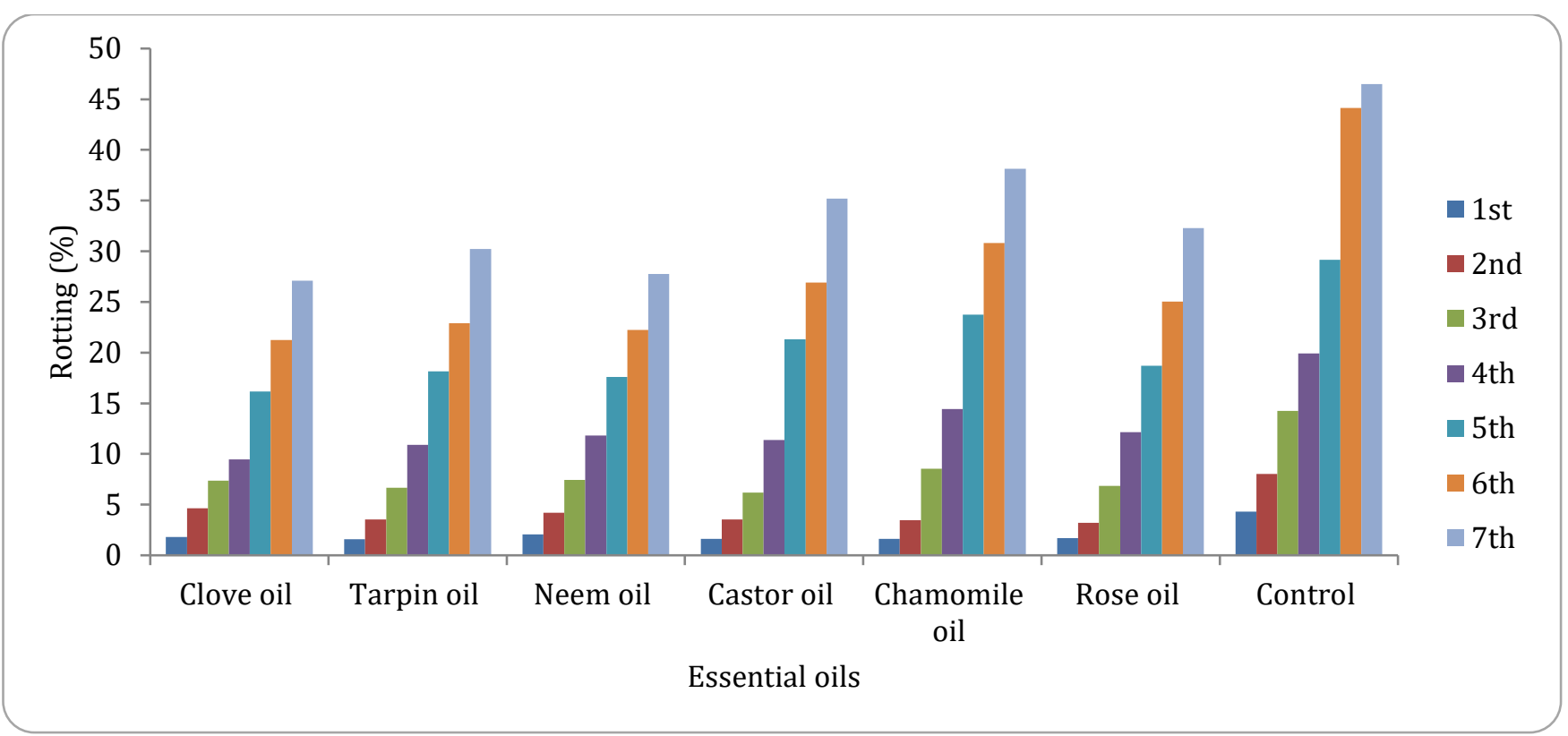

Figure 3. Evaluation of rotting (\%) of lemon fruits through direct contact with aqueous solution of essential oils.

\section{DISCUSSIONS}

Lemon fruits of the local market of Hyderabad and Tando Jam found with varying incidence of different types of post-harvest rots. Among the rots, fruit rot of lemon found to be the most severe disease throughout the survey districts. In order to reduce the side effect of chemicals, an alternative method is introduced through this study for controlling the fruit rot of lemon. In this regards, some essential oils found to have promising history for the antimicrobial activity against a number of plant diseases. In present study six different oils such as clove, tarpin, neem, castor, chamomile and rose oil are used against fruit rot of lemon caused by $A$. niger under in-vitro conditions. In-vitro test against $A$. niger by the effect of volatile produced by essential oils or by the amendment of oils in the media revealed a great variation of fungal growth diameter among different treatments.Volatile effect of few essential oils are highly effective-completely inhibited the growth of A. niger, few were moderately effective-brought some reduction in the growth, while few were almost ineffective and failed to check the growth of the test pathogen.

Direct mixing of clove oil with media shows almost $100 \%$ inhibition of $A$. niger at all the used doses. The second most effective oil remains tarpin. The antifungal property of clove oil is determined by numerous researchers (Baratta et al., 1998). The mycelial growth of post-harvest fungal pathogens isolated from Embul banana can be reduced by the use of clove oil
(Ranasinghe et al., 2002). Alrajhi, (2014) evaluated the effects essential oils extracted from Cinnamon, tea-tree and lemon grass against fungal pathogens of cinnamon viz. Curvularia, Helminthosporium, Pestalotiopsis, Aspergillus, Rhizopus, Cladosporium, Nigrospora and Trichoderma. On the other hand all the other used oil viz., castor, chamomile and rose oil also reduced the growth of the targeted pathogen but in most of the cases at higher used concentrations. Sitara et al. (2008) evaluated antifungal activity of neem seed EO against Aspergillus niger, A. flavus, Fusarium oxysporum, $F$. moniliforme, $F$. nivale, $F$. semitectum, Drechsleraha wiinesis and Alternaria alternata.

A number of fresh and healthy lemon fruits were inoculated with Aspergillus niger using cut and injection method of inoculations. In cut method, some mature lemon fruits were inoculated from 8-10 days old pure culture disc of $A$. niger in the cut made in the lemon fruits using sterilized cutter. While in injection method, the lemon fruits were inoculated with the aqueous solution of same pathogen ( $1 \mathrm{ml}$ of pathogen solution) using syringe needle. The inoculated portions of the lemon fruits were covered with the paraffin film as to check the invasion of other pathogens. Both the inoculated lemon samples were observed for 07 days. It is found that high severity of disease was determined through cut method of inoculation as compared to injection method. Clove oil ranked $1^{\text {st }}$, tarpin oil ranked $2^{\text {nd }}$, neem oil ranked $3^{\text {rd }}$, castor oil ranked $4^{\text {th }}$, chamomile 
oil ranked $5^{\text {th }}$, rose oil ranked $6^{\text {th }}$ for controlling the linear colony growth of $A$. niger under in-vitro conditions. The antifungal ability of EO found to be challenging to combat A.niger and is actually in accordance with the findings of Pawar and Thaker (2006). For further study of effectiveness of essential oils, the inoculated lemon fruits were immersed in aqueous solution of essential oils. Minimum rotting $(12.53 \%)$ was recorded for clove oil followed by neem oil $(13.30 \%)$, tarpin oil $(13.42 \%)$, rose oil $(14.27 \%)$, castor oil (15.16\%) and chamomile oil (17.25\%), respectively. Findings published by Guynot et al., (2003) and Viuda-Martos et al., (2007) are in agreement with the results obtained in our experiment. The method described in this study may be used on a broader level for obtaining a qualitative result and it will be no more than an idea about the volatile fraction of EOs.

Attack of different biotic and abiotic factors, can affect the production of lemon fruit and cause severe problems to the growers (Timmer and Graham, 1992). In 2014 survey, lemon fruit displayed wrinkled dark brown lesion in citrus production at Islamabad, Taxila, Rawalpindi and Wah districts, Pakistan. The severity of disease was higher $(36.6 \%)$ in Islamabad followed by Rawalpindi (23\%), Taxila (23\%) and Wah (20\%), correspondingly. Around $20 \%$ vegetable and fruits spoilage are associated with the damages caused by a variety of fungi. A study has been carried out to identify the fungi causing spoilt in fruits sold in the market of Gwagwalada, Abuja. According to their findings Aspergillus niger was one of the most prominent fungi which causing spoilage in lemon, oranges, pawpaw, pineapple, watermelon with a frequency (38\%) followed by Fusarium avenaceum (31\%), Penicillium digitatum and Rhizopus stolonifer (4\%), Saccharomyces species (10\%), Fusarium solani (8\%), Aspergillus flavus (5\%), respectively. A. niger were highly prevalent in orange (70\%) followed by $F$. avenaceum (65\%) in pawpaw. Saccharomyces species (40\%) in watermelon, $P$. digitatum (20\%) in tomato and $R$. stolonifer (5\%) in orange, respectively (Samuel et al., 2017).

\section{CONCLUSION}

On the basis of present investigation it is concluded that pathogenicity test against $A$. niger through cut method is more severe than that of injection method. Similarly, for controlling the linear colony growth of $A$. niger under in vitro conditions clove oil ranked $1^{\text {st }}$, tarpin oil ranked $2^{\text {nd }}$, neem oil ranked $3^{\text {rd }}$, castor oil ranked $4^{\text {th }}$, chamomile oil ranked $5^{\text {th }}$, and rose oil ranked $6^{\text {th }}$. The effect of EOs can also be shown by the numerous rotting percentages in lemon through direct contact of inoculated fruit samples with the aqueous solution of different essential oils.

\section{RECOMMENDATIONS}

As per conclusion it is suggested that clove oil may be used for controlling $A$. niger causing fruit rot of lemon. Furthermore, studies should be conducted to find the efficiency of clove oil against other fungal species on various fruits and vegetables.

\section{REFERENCES}

Ahmed, D. M., S. El-Shami and M. H. El-Mallah. 2007. Jojoba oil as a novel coating for exported Valencia orange fruit. Part 1. The use of trans (isomerized) jojoba oil. American-Eurasian journal of agricultural \& environmental sciences. 2: 173-181.

Alrajhi, A. M. H. 2014. Impact of plant oils as antifungal activity against fungal pathogens of Cinnamomum zeylanicum (Cinnamon). International Journal of Medical and Health Sciences Research, 1: 1-12.

Arras, G. and M. Usai. 2001. Fungitoxic Activity of 12 Essential Oils against Four Postharvest Citrus Pathogens: Chemical Analysis of Thymus capitatus Oil and its Effect in Subatmospheric Pressure Conditions. Journal of Food Protection, 64: 10251029.

Bakkali, F., S. Averbeck, D. Averbeck and M. Idaomar. 2008. Biological effects of essential oils - A review. Food and Chemical Toxicology, 46: 446-475.

Baratta, M. T., H. J. D. Dorman, S. G. Deans, A. C. Figueiredo, J. G. Barroso and G. Ruberto. 1998. Antimicrobial and antioxidant properties of some commercial essential oils. Flavour and Fragrance Journal, 13: 235-244.

Gomi, K., H. Yamamato and K. Akimitsu. 2003. Epoxide hydrolase: a mRNA induced by the fungal pathogen Alternaria alternata on rough lemon (Citrus jambhiri Lush). Plant molecular biology, 53: 189-199.

Guynot, M. E., A. J. Ramos, L. Seto, P. Purroy, V. Sanchis and S. Marin. 2003. Antifungal activity of volatile compounds generated by essential oils against fungi commonly causing deterioration of bakery products. Journal of Applied Microbiology, 94: 893-899.

Inouye, S., K. Uchida, N. Maruyama, H. Yamaguchi and S. Abe. 2006. A novel method to estimate the contribution of the vapor activity of essential oils 
in agar diffusion assay. . Journal of Japanes Medical Mycology, 47: 91-98.

Klieber, A., E. Scott and E. Wuryatmo. 2002. Effect of method of application on antifungal efficacy of citral against postharvest spoilage fungi of citrus in culture. Australasian Plant Pathology, 31: 329.

Ladanyia, M. and M. Ladaniya. 2010. Citrus fruit: biology, technology and evaluation. Academic press.

Lassois, L., L. de Lapeyre de Bellaire and M. H. Jijakli. 2008. Biological control of crown rot of bananas with Pichia anomala strain $\mathrm{K}$ and Candida oleophila strain 0. Biological Control, 45: 410-418.

Moss, M. O. 2002. Mycotoxin review. Aspergillus and Penicillium. Mycologist, 16: 116-119.

Pawar, V. and V. Thaker. 2006. In vitro efficacy of 75 essential oils against Aspergillus niger. Mycoses, 49: 316-323.

Ranasinghe, L., B. Jayawardena and K. Abeywickrama. 2002. Fungicidal activity of essential oils of Cinnamomum zeylanicum (L.) and Syzygium aromaticum (L.) Merr et L.M.Perry against crown rot and anthracnose pathogens isolated from banana. Letters in Applied Microbiology, 35: 208211.

Sabir, H. M., M. B. Khan and Z. Hussain. 2010. Marketing Margin of Mandarin: A Case Study of Sargodha Region, Pakistan. Pakistan Journal of Social Sciences (PJSS), 30.

Sabulal, B., D. Mathew, S. P. Nediyamparambu, R. K. Valsamma and G. Varughese. 2006. Composition and antimicrobial activity of essential oil from the fruits of Amomum cannicarpum. Acta Pharmaceutica, 56: 473-480.

Samuel, M., H. O. God'spower Richard Okoh, K. Olabode and R. Osanupin. 2017. Isolation and identification of fungi associated with spoilt fruits vended in Gwagwalada market, Abuja, Nigeria. Veterinary world, 10: 393.

Sitara, U., I. Niaz, J. Naseem and N. Sultana. 2008. Antifungal effect of essential oils on in vitro growth of pathogenic fungi. Pakistan Journal of Botany, 40: 409.

Spina, S., V. Coco, A. Gentile, A. Catara and G. Cirvilleri. 2008. Association of Fusarium solani with rolabc and wild type Troyer citrange. Journal of Plant Pathology: 479-486.

Terol, J., A. Conesa and J. M. Colmenero, M. Cercos, F. Tadeo, J. Agusti, E. Alos, F. Andres, G. Soler, J. Brumos, D. J. Iglesias, S. Gotz, F. Leqaz, X. Argout, B. Courtois, P. Ollitrault, C. Dossat, P.Wincker, R. Morillon and M. Talon. 2014. Analysis of 13000 unique Citrus clusters associated with fruit quality, production and salinity tolerance. B.M.C. Genomics, 8: 31.

Timmer, L. W. 1992. Nontransmission of Citrus Blight by Soil. Plant Disease, 76: 323D.

Viuda-Martos, M., Y. Ruiz-Navajas, J. Fernandez-Lopez and J. A. Perez-Alvarez. 2007. Antifungal activities of thyme, clove and orange essential oils. Journal of Food Safety, 27. 